\title{
Hydration to Maximize Performance And Recovery: Knowledge, Attitudes, and Behaviors Among Collegiate Track and Field Throwers
}

\author{
by \\ Lawrence W. Judge1, David M. Bellar2, Jennifer K. Popp ${ }^{3}$, Bruce W. Craig', \\ Makenzie A. Schoeff', Donald L. Hoover ${ }^{4}$, Brian Fox ${ }^{1}$, Brandon M. Kistler ${ }^{5}$, \\ Ali M. Al-Nawaiseh ${ }^{6}$
}

Hydration plays an important role in performance, injury prevention, and recovery for athletes engaged in competitive sports. Therefore, it is important that strength and conditioning coaches understand an athlete's hydration needs to prevent illness and enhance performance. The purpose of this study was to identify hydration knowledge, attitudes, and behaviors of collegiate track and field throwers, as well as identify barriers to hydration and sources of nutritional information. The Rehydration and Refueling in Collegiate Track and Field Throwers Survey was sent to 271 track and field thrower coaches with a request to forward the email to current track and field throwers. Pearson correlation coefficients were calculated regarding knowledge, attitude, and behavior scores among the participants in this sample. Differences among response patterns were assessed via Chi-square analysis. Alpha level was set at $p=.05$. Results demonstrated that $97.3 \%(n=287)$ of respondents knew that dehydration would decrease performance, but $50.5 \%(n=149)$ erroneously believed thirst was the best indicator of dehydration. Chi-square analysis demonstrated a significant difference in reported values between participants who intended to eat a performance-enhancing diet and those who consumed less fluid than recomended values $(207-295 \mathrm{~m}) \mathrm{l}$ in the 2-3 hours prior to competition $(\chi 2=$ $10.87, p<.05)$. Pearson correlation coefficients demonstrated a large association between knowledge and behavior $(r=$ $.70, p<.05)$, a medium association between knowledge and attitude $(r=.41, p<.05)$, and a small association between attitude and behavior $(r=.21, p<.05)$. This suggests that strength and conditioning coaches and health staff need to educate and monitor hydration behaviors among collegiate track and field throwers to optimize performance.

Key words: carbohydrates, hypohydration, thirst.

\section{Introduction}

Collegiate athletes in the United States of America generally recognize the importance of proper hydration during physical activity (Nichols et al., 2005; Volpe et al., 2009). However, some individuals lack the knowledge and resources needed to adequately rehydrate and refuel during physical activity, which could then lead to detriments in performance. In fact, $66 \%$ of National Collegiate Athletic Association (NCAA)

1 - School of Kinesiology, Ball State University, Muncie, IN, United States.

2 - Department of Kinesiology, University of North Carolina at Charlotte, Charlotte, NC, United States.

3 - College of Health and Human Sciences, Purdue University, Lafayette, IN, United States.

4 - Department of Physical Therapy, Western Michigan University, Kalamazoo, MI, United States.

5 - Department of Nutrition and Health Science, Ball State University, Muncie, IN, United States.

6 - College of Physical Education and sport sciences, The Hashemite University, Zarqa, Jordan. 
Division I athletes at a single university were found to be in a state of hypohydration prepractice (Volpe et al., 2009). Hypohydration stresses the cardiovascular system and reduces physical capacity, placing an athlete at a higher risk for musculoskeletal injury (Berning and Steen, 1991). In order to implement a successful hydration protocol, it is important that athletes, coaches, athletic trainers, and strength and conditioning professionals understand the importance of maintaining proper hydration and nutrition, as well as the critical components of hydration education (Casa et al., 2000).

The risks of dehydration and potential consequences to performance can be unique to track and field athletes, as their fluid needs are highly variable as a result of the diverse nature of events, training programs, and individual differences among athletes (Casa et al., 2019). Sweating rates among track and field athletes can range from 0.5 to $3.0 \mathrm{~L} / \mathrm{hr}$ (Baker et al., 2016) due to differences in factors such as body size, exercise intensity, exercise duration, environment, and choice of clothing (Casa et al., 2019). Although the influence of dehydration on performance has been extensively studied in endurance exercise, how it impairs performance in sports that require repeated bouts of short-term high intensity efforts is not as well studied (Maughan and Shirreffs, 2010). A review of the effects of dehydration on muscle strength, power, and high-intensity anaerobic capacity demonstrated that dehydration could have an impact on strength and power. Cheuvront and Kenefick (2014) reported that $\geq 2 \%$ dehydration impaired endurance exercise performance mediated by body water volume loss. According to Judelson et al. (2007) hypohydration appears to consistently attenuate strength (by approximately $2 \%$ ), power (by approximately 3\%) and high-intensity endurance (by approximately 10\%). According to a meta-analysis by Savoie et al. (2015), hypohydration caused muscle strength to fall by $5.5 \pm 1.0 \%(p<0.05)$ and anaerobic power fell $(-5.8$ $\pm 2.3 \%)$. This suggests alterations in total body water can affect some aspects of force generation. According to research examining differences between euhydrated and dehydrated conditions, there is a direct connection between body water deficits ( $2.9 \%$ of body mass) and an athlete's ability to generate upper and lower body anaerobic power (Jones et al., 2008). Therefore, it is important for track and field athletes competing in events such as jumping, throwing, sprints, and multi-events to begin training and competition in a state of optimal hydration and consume sufficient fluid during exercise to optimize performance and health (Casa et al., 2019).

Despite awareness of the status of dehydration and the negative effect it may have on performance, athletes often fail to practice appropriate hydration strategies. For example, previous research has shown that athletes generally lack knowledge of the appropriate markers for self-regulating adequate hydration levels (O'Neal et al., 2011; Yeargin et al., 2010). This may include a lack of clarity about appropriate targets for fluid intake, beverage types, and important information to monitor. Athletes are often unaware of the best methodologies for determining hydration status such as urine specific gravity, urine color, changes in body mass, plasma osmolality and bioimpedance. The National Athletic Trainers' Association (NATA) recommends the following practices regarding fluid replacement for athletic participation: athletes should begin a training session well hydrated by drinking approximately 500 to $600 \mathrm{ml}$ of water or sports drink 2 to 3 hours before exercise and additional 200 to $300 \mathrm{ml}$ of water or a sports drink 10 to $20 \mathrm{~min}$ before exercise. During the training session fluid replacement should approximate sweat and urine losses and maintain hydration at a level that keeps body weight loss to $<2 \%$. This can generally be achieved by the consumption of 200 to $300 \mathrm{ml}$ of fluid every 10 to $20 \mathrm{~min}$. Post-activity hydration should aim to correct any fluid loss accumulated during the practice or competition. Water quality and alkalinity are also factors to consider for fluid replacement as alkaline mineral water has been shown to potentially offer advantages in hydration post-exercise (Chycki et al., 2017). Additionally, research has shown that mineral content for tap and bottled water varies by region (Azoulay et al., 2001), therefore it may be important for coaches and athletes to be aware of the quality and composition of locally available water sources.

Specific recommendations for individual athletes depend on body mass, sweat rate, environment and tolerance (Casa et al., 2000). In 
addition to limited knowledge, athletes face many unique barriers that prevent the specific application of that knowledge. This may be especially true for the throwing events in track and field (Judge et al., 2013) which are often segregated from the other events due to safety concerns (Judge et al., 2010). Thus, while hydration in endurance events have been extensively investigated, the effects of hydration in other areas of track and field, especially throwing, have yet to be clearly defined. Therefore, the purpose of this study was to identify knowledge, attitudes, and behaviors among a sample of NCAA collegiate track and field throwers (CTFTs) related to current science regarding hydration (Nichols et al., 2005).

\section{Methods}

\section{Participants}

The CTFTs from all three NCAA divisions participated in this study. Eligible participants met the following inclusion criteria: 1) current member of a track and field team, 2) designated as a thrower on that team, and 3) between the ages of 18-40 years. Three hundred twenty-four (324) participants $(20.11 \pm 3.29$ years of age $)$ met these inclusion criteria and responded to the survey. This study received university Institutional Review Board approval for exempt research prior to initiation of the study. Participants were informed of the benefits and potential risks of the investigation and completion of the online survey served as the participants' consent to participate.

\section{Measures}

The Rehydration and Refueling in Collegiate Track and Field Throwers Survey (RRCTFS), which consisted of 79 questions, was used to collect responses. The survey was developed based on previous research (Judge et al., 2016) as well as the position stands on hydration published by the American College of Sport Medicine (ACSM) (Sawka et al., 2007) and the National Athletic Trainers' Association (NATA) (Casa et al., 2000). The survey was constructed at a reading level that could be easily understood, with terms like "sports drink" being used in the place of technical jargon such as carbohydrate-electrolyte beverage. The first section of the survey included demographic questions. The second section included true/false questions to assess knowledge of proper hydration practices based on current research while the third section included Likert-type statements (strongly agree to strongly disagree) to evaluate attitudes towards recommended hydration practices. The fourth section attempted to identify behaviors of participants regarding hydration through yes/no questions, while the fifth section included Likert-type statements (strongly agree to strongly disagree) to identify participants' sources of nutrition information. The sixth and final section included yes/no questions designed to assess personal habits regarding nutrition and fluid consumption as well as barriers to proper nutrition and fluid consumption.

Content validity was established in two ways. The survey was reviewed by a panel of experts that included one certified athletic trainer (ATC), one registered dietician (RD), two certified strength and conditioning specialists (CSCS) and two National Strength and Conditioning Association fellows (FNSCA). After a careful review of the survey instrument, the panel of experts made no substantive changes to the instrument, but did alter some of the wording to enhance the clarity of the survey. Items contained in the knowledge section demonstrated high internal consistency with a Cronbach's alpha coefficient of 0.906, while the attitude and behavior section exhibited internal consistency with a Cronbach's alpha coefficient of 0.438 and 0.925 , respectively. This survey was created and distributed using Qualtrics survey application software (Version 51902; Qualtrics, Provo, UT) loaded onto the university server.

To test the reliability of the RRCTFS instrument, researchers administered the instrument in a test-retest manner to a pilot sample that consisted of 20 former track and field throwers that were current professional coaches, recruited from a coaching education course. In the pilot testing, both the knowledge scores were not significantly different pre to post in a sample testretest reliability study $(\mathrm{n}=20, p>0.05)$ that examined the stability of the survey after a onemonth time period. The correlation $(r>0.8)$ was then calculated according to each question and in the total of all questions between the first and second applications. Given the correlations between two separate administrations, it appears that the instrument had satisfactory reliability. 
This instrument demonstrated low item to total correlations $(\mathrm{r}<0.19)$, suggesting that items measured different constructs as was the intention when the survey was designed.

\section{Design and Procedures}

The research design is a descriptive survey study. A database of head track and field throws coaches (or head coaches, if unable to identify a throws coach) was generated. An email was sent to 271 coaches with a request to forward the email to all current track and field throwers. This email included the purpose of the study, a brief description of the survey, estimated time to complete, and consent procedures along with a hyperlink to the web-based survey. A follow-up email was sent bi-weekly for the four weeks following the initial email, thanking those who participated as well as serving as a reminder for those who had not yet completed the survey.

\section{Statistical Analysis}

A power analysis to determine appropriate sample size was conducted using the results from Judge et al. (2016) where a moderate effect size was revealed using 100 participants. The analysis suggested that a sample size of 150 or greater participants was adequate to determine appropriate differences in responses. The completed survey responses were stored in the Qualtrics software application loaded on the university server. At the end of data collection, survey responses were downloaded and analyzed using IBM SPSS Statistics for Windows (version 23; IBM Corp., Armonk, NY). Descriptive statistics were used to calculate percentages, averages, and frequency of responses. Pearson correlation coefficients were calculated regarding knowledge, attitude, and behavior scores among the participants in this sample. Differences among response patterns were assessed via Chi-square analysis. The alpha level was set at $p=0.05$.

\section{Results}

Participant demographics are included in Table 1. The findings were separated into three thematic categories: knowledge, attitudes, and behaviors. Knowledge was operationally defined as a set of understandings or beliefs on the topic grounded in science. Attitudes were defined as "leaning to" or "tendencies to" as attitudes frequently serve as a bridge between knowledge and practices, yet numerous studies show that a weak relationship exists between knowledge and practices. Pearson correlation analysis revealed several significant positive correlations between knowledge, attitude, and behavior scores of participants (Table 2).

\section{Knowledge}

There were 295 participants who completed all items on the survey related to the assessment of hydration knowledge. The CTFTs reported that dehydration may decrease athletic performance $(97.3 \%, \mathrm{n}=287)$, fluids should be consumed during practice $(99.7 \%, \mathrm{n}=294)$, and fluids should be readily available during practice and competition (Table 3). Also, throwers appeared aware of pre-competition recommendations for hydration, as $90.2 \%$ ( $\mathrm{n}=$ 266) indicated that $503-591 \mathrm{ml}$ of fluid should be consumed a few hours before competition, and $67.8 \%(n=200)$ indicated that $207-295 \mathrm{ml}$ of fluid should be consumed 10-20 minutes before competition. Table 3 summarizes the hydration knowledge of CTFTs.

There were a few areas where respondents demonstrated a lack of knowledge. Just over half of the participants $(50.5 \%, \mathrm{n}=149)$ erroneously believed that thirst was the best indicator of dehydration. The use of sports drinks was evidently another area of confusion. Only 122 (41.4\%) indicated that sports drinks were superior to water in restoring muscle glycogen. Also, only $67.5 \%(n=199)$ of throwers indicated that a sports drink should be consumed within two hours after exercise.

Attitudes

There were 295 participants who completed all items related to attitudes on hydration. The CTFTs' attitudes pertaining to hydration are highlighted in Table 4. 93.9\% ( $\mathrm{n}=$ 284) of CTFTs indicated that dehydration would decrease athletic performance, and $75 \%(n=224)$ did not believe that they should rely on thirst alone as an indicator of dehydration. Participants indicated that fluids should be consumed during practice $(97.9 \%, \mathrm{n}=289)$ and readily available during practice and competition (Table 4). The majority $(81.3 \%, \mathrm{n}=240)$ believed that $503-591$ $\mathrm{ml}$ of fluid should be consumed a few hours before competition, but only 59.7\% ( $\mathrm{n}=176)$ indicated that $207-295 \mathrm{ml}$ of fluid should be consumed 10-20 min prior to competition. A total of $92.5 \%(\mathrm{n}=273)$ of CTFTs indicated that 
monitoring the color of urine would identify the presence of dehydration, and $93.5 \%(\mathrm{n}=275)$ believed that excessive sweating, thirst, and muscle cramping were signs of dehydration. However, only $50.9 \%(\mathrm{n}=150)$ believed that weighing themselves before and after practice was a good way to determine fluid loss during practice. Only $27.5 \%(n=81)$ believed that sports drinks were superior to water in restoring muscle glycogen. Furthermore, $30.5 \%(\mathrm{n}=90)$ were unsure whether a sports drink should be consumed within two hours of exercise.

\section{Behavior}

There were 295 participants who completed all items on the survey related to hydration behaviors. Table 5 highlights the behaviors of CTFTs regarding hydration. Most CTFTs $(89.5 \%, \mathrm{n}=246)$ indicated that they drank plenty of fluids to avoid decreased performance caused by dehydration, while $81.8 \%(\mathrm{n}=225)$ reported that they did not use thirst alone as an indicator of dehydration. The majority $(93.5 \%, \mathrm{n}=$ 257) of participants indicated that they consumed fluids during practice, and many reported that fluids were readily available during practice and competition (Table 5). Furthermore, 78.5\% ( $\mathrm{n}=$ 216) drank $503-591 \mathrm{ml}$ of fluid a few hours before competition, and $62.2 \%(\mathrm{n}=171)$ consumed $207-295 \mathrm{ml}$ of fluid $10-20 \mathrm{~min}$ prior to competition. The majority of CTFTs $(88.7 \%, \mathrm{n}=$ 244) monitored the color of their urine to determine dehydration, and $86.5 \%(\mathrm{n}=238)$ used excessive sweating, thirst, and muscle cramping as warning signs of dehydration. A significant difference in reported values was found between participants who intended to eat a performance enhancing diet and those who consumed 503 $591 \mathrm{ml}$ of fluid a few hours before competition $\left(\chi^{2}\right.$ $=10.87, p<.05$ ). There were no other significant differences or associations identified between those who intended to eat a performance enhancing diet and their hydration behaviors.

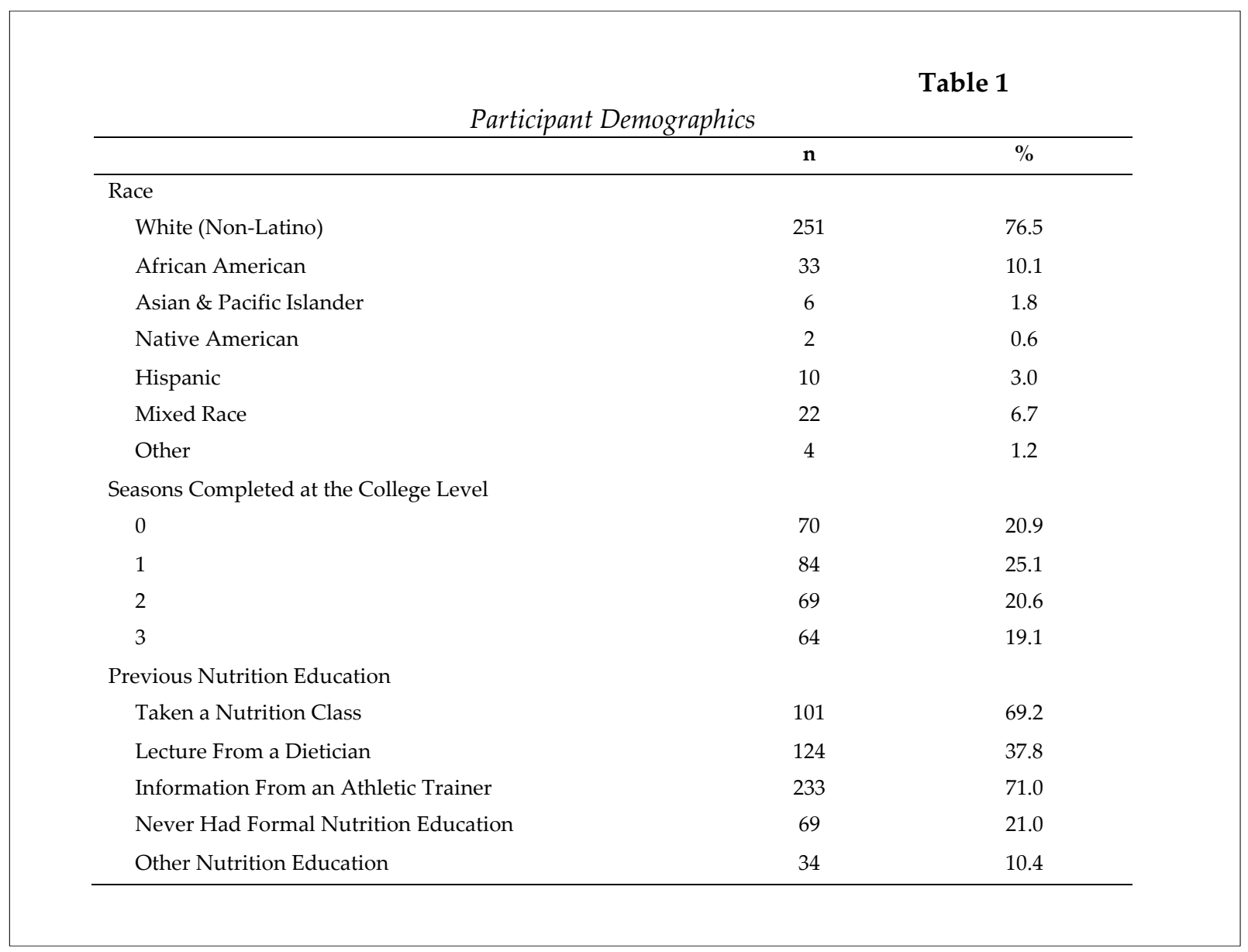


Table 2

Pearson Correlations Coefficients Between Knowledge, Attitude, and Behavior Scores of Collegiate Track and Field Throwers Regarding Hydration

\begin{tabular}{cccc}
\hline & Knowledge & Attitude & Behavior \\
\hline Knowledge & 1.0 & & \\
Attitude & $0.41^{*}$ & 1.0 & \\
Behavior & $0.70^{*}$ & $0.21^{*}$ & 1.0 \\
\hline & $*$ indicates significance at $p<.01$
\end{tabular}

Table 3

Hydration Knowledge of NCAA Track and Field Throwers, No. (\%)

\begin{tabular}{|c|c|c|}
\hline Item & True & False \\
\hline $\begin{array}{l}\text { Using salt tablets keeps athletes from getting dehydrated during training and } \\
\text { competition. (F) }\end{array}$ & $63(21.4)$ & $232(78.6)$ \\
\hline Dehydration decreases athletic performance. $(\mathrm{T})$ & $287(97.3)$ & $8(2.7)$ \\
\hline Thirst is the best indicator of dehydration. (F) & $149(50.5)$ & $146(49.5)$ \\
\hline An athlete should not drink water or any fluids during practice. $(\mathrm{F})$ & $1(.3)$ & $294(99.7)$ \\
\hline Coaches should not let athletes drink any fluids during practice. (F) & $2(.6)$ & $293(99.3)$ \\
\hline Coaches should not let athletes drink any fluids during competition. $(\mathrm{F})$ & $0(0)$ & $295(100)$ \\
\hline It is important for fluids to be readily available to athletes during practice. (T) & $294(99.7)$ & $1(0.3)$ \\
\hline $\begin{array}{l}\text { It is important for fluids to be readily available to athletes during } \\
\text { competition. }(\mathrm{T})\end{array}$ & $291(98.6)$ & $4(1.4)$ \\
\hline Within 2 hours after exercise, athletes should drink a sports drink. (T) & $199(67.5)$ & $96(32.5)$ \\
\hline $\begin{array}{l}\text { Sports drinks are better than water because they restore glycogen in muscles. } \\
\text { (T) }\end{array}$ & $122(41.4)$ & $173(58.6)$ \\
\hline $\begin{array}{l}\text { An athlete should drink } 503-591 \mathrm{ml} \text { of water or a sports drink a couple of } \\
\text { hours before competition. }(\mathrm{T})\end{array}$ & $266(90.2)$ & $29(9.8)$ \\
\hline $\begin{array}{l}\text { An athlete should drink } 207-295 \mathrm{ml} \text { of water or a sports drink } 10-20 \mathrm{~min} \\
\text { before competition. (T) }\end{array}$ & $200(67.8)$ & $95(32.2)$ \\
\hline $\begin{array}{l}\text { When exercising for more than } 1 \text { hour, an athlete should drink a sports drink } \\
\text { rather than water. (T) }\end{array}$ & $122(41.4)$ & $173(58.6)$ \\
\hline $\begin{array}{l}\text { By monitoring the color of urine, an athlete can judge if he/she is dehydrated. } \\
\text { (T) }\end{array}$ & $281(95.3)$ & $14(4.7)$ \\
\hline $\begin{array}{l}\text { A good way for an athlete to determine how much water or sports drink to } \\
\text { consume after practice is to obtain body weight before and after practice. (T) }\end{array}$ & $187(63.4)$ & $108(36.6)$ \\
\hline Excessive sweating, thirst, and muscle cramping are signs of dehydration. (T) & $280(95.6)$ & $13(4.4)$ \\
\hline $\begin{array}{l}\text { More than two drinks of alcohol the day before practice and/or competition } \\
\text { can lead to dehydration. }(\mathrm{T})\end{array}$ & $286(96.9)$ & $9(3.1)$ \\
\hline
\end{tabular}


Table 4

Hydration Attitudes of NCAA Track and Field Throwers, No. (\%)

Item
I believe using salt tablets keeps me from getting dehydrate
during training and competition.
I believe dehydration decreases my athletic performance.
I believe I can rely on thirst alone as an indicator of
dehydration.
I believe no water or fluids should be consumed during
practice.

I believe my coach should not let athletes drink any fluids during practice.

I believe my coach should not let athletes drink any fluids during competition.

I believe fluids should be readily available to me during practice.

I believe fluids should be readily available to me during competition.

I believe I should drink a sports drink within 2 hours after exercise.

I think sports drinks are better than water because they restore glycogen in muscles.

I believe I should drink $503-591 \mathrm{ml}$ of water or a sports drink a couple of hours before competition.

I believe I should drink $503-591 \mathrm{ml}$ of water or a sports drink 10-20 minutes before competition.

I believe when exercising for more than 1 hour, I should drink a sports drink rather than water.

I believe by monitoring the color of my urine, I can judge if I am dehydrated.

I believe weighing myself before and after practice is a good way to determine how much fluid I lost.

I believe excessive sweating, thirst, and muscle cramping are signs of dehydration.

I believe drinking more than two drinks of alcohol the day before competing can lead to dehydration.

\begin{tabular}{|c|c|c|c|c|}
\hline SD & D & Un & $\mathbf{A}$ & SA \\
\hline $\begin{array}{c}68 \\
(23.1)\end{array}$ & $\begin{array}{c}87 \\
(29.5)\end{array}$ & $\begin{array}{c}120 \\
(40.7)\end{array}$ & $\begin{array}{c}16 \\
(5.4)\end{array}$ & $\begin{array}{c}4 \\
(1.4)\end{array}$ \\
\hline $\begin{array}{c}2 \\
(0.6)\end{array}$ & $\begin{array}{c}6 \\
(1.8)\end{array}$ & $\begin{array}{c}3 \\
(0.9)\end{array}$ & $\begin{array}{c}58 \\
(17.3)\end{array}$ & $\begin{array}{c}226 \\
(76.6)\end{array}$ \\
\hline $\begin{array}{c}84 \\
(28.5)\end{array}$ & $\begin{array}{c}140 \\
(47.5)\end{array}$ & $\begin{array}{c}22 \\
(7.5)\end{array}$ & $\begin{array}{c}40 \\
(13.6)\end{array}$ & $\begin{array}{c}9 \\
(3.1)\end{array}$ \\
\hline $\begin{array}{c}239 \\
(81.0)\end{array}$ & $\begin{array}{c}50 \\
(16.9)\end{array}$ & $\begin{array}{c}3 \\
(1.0)\end{array}$ & $\begin{array}{c}0 \\
(0)\end{array}$ & $\begin{array}{c}3 \\
(1.0)\end{array}$ \\
\hline $\begin{array}{c}248 \\
(84.1)\end{array}$ & $\begin{array}{c}40 \\
(13.6)\end{array}$ & $\begin{array}{c}2 \\
(0.7)\end{array}$ & $\begin{array}{c}1 \\
(0.3)\end{array}$ & $\begin{array}{c}4 \\
(1.4)\end{array}$ \\
\hline $\begin{array}{c}239 \\
(81.0)\end{array}$ & $\begin{array}{c}49 \\
(16.6)\end{array}$ & $\begin{array}{c}3 \\
(1.0)\end{array}$ & $\begin{array}{c}0 \\
(0)\end{array}$ & $\begin{array}{c}4 \\
(1.4)\end{array}$ \\
\hline $\begin{array}{c}1 \\
(0.3)\end{array}$ & $\begin{array}{c}0 \\
(0)\end{array}$ & $\begin{array}{c}4 \\
(1.4)\end{array}$ & $\begin{array}{c}65 \\
(22.0)\end{array}$ & $\begin{array}{c}225 \\
(76.3)\end{array}$ \\
\hline $\begin{array}{c}0 \\
(0)\end{array}$ & $\begin{array}{c}0 \\
(0)\end{array}$ & $\begin{array}{c}4 \\
(1.4)\end{array}$ & $\begin{array}{c}65 \\
(22.0)\end{array}$ & $\begin{array}{c}226 \\
(76.6)\end{array}$ \\
\hline $\begin{array}{c}4 \\
(1.4)\end{array}$ & $\begin{array}{c}37 \\
(12.5)\end{array}$ & $\begin{array}{c}90 \\
(30.5)\end{array}$ & $\begin{array}{c}111 \\
(37.6)\end{array}$ & $\begin{array}{c}53 \\
(18.0)\end{array}$ \\
\hline $\begin{array}{c}18 \\
(6.1)\end{array}$ & $\begin{array}{c}98 \\
(33.2)\end{array}$ & $\begin{array}{c}98 \\
(33.2)\end{array}$ & $\begin{array}{c}63 \\
(21.4)\end{array}$ & $\begin{array}{c}18 \\
(6.1)\end{array}$ \\
\hline $\begin{array}{c}12 \\
(4.1)\end{array}$ & $\begin{array}{c}0 \\
(0)\end{array}$ & $\begin{array}{c}43 \\
(14.6)\end{array}$ & $\begin{array}{c}173 \\
(58.6)\end{array}$ & $\begin{array}{c}67 \\
(22.7)\end{array}$ \\
\hline $\begin{array}{c}4 \\
(1.4)\end{array}$ & $\begin{array}{c}37 \\
(12.5)\end{array}$ & $\begin{array}{c}78 \\
(26.4)\end{array}$ & $\begin{array}{c}135 \\
(45.8)\end{array}$ & $\begin{array}{c}41 \\
(13.9)\end{array}$ \\
\hline $\begin{array}{c}18 \\
(6.1)\end{array}$ & $\begin{array}{c}93 \\
(31.5)\end{array}$ & $\begin{array}{c}81 \\
(27.5)\end{array}$ & $\begin{array}{c}79 \\
(26.8)\end{array}$ & $\begin{array}{c}24 \\
(8.1)\end{array}$ \\
\hline $\begin{array}{c}2 \\
(0.7)\end{array}$ & $\begin{array}{c}8 \\
(2.7)\end{array}$ & $\begin{array}{c}12 \\
(4.1)\end{array}$ & $\begin{array}{c}126 \\
(42.7)\end{array}$ & $\begin{array}{c}147 \\
(49.8)\end{array}$ \\
\hline $\begin{array}{c}13 \\
(4.4)\end{array}$ & $\begin{array}{c}56 \\
(19.0)\end{array}$ & $\begin{array}{c}76 \\
(25.8)\end{array}$ & $\begin{array}{c}104 \\
(35.3)\end{array}$ & $\begin{array}{c}46 \\
(15.6)\end{array}$ \\
\hline $\begin{array}{c}2 \\
(.7)\end{array}$ & $\begin{array}{c}6 \\
(2.0)\end{array}$ & $\begin{array}{c}11 \\
(3.7)\end{array}$ & $\begin{array}{c}118 \\
(40.1)\end{array}$ & $\begin{array}{c}157 \\
(53.4)\end{array}$ \\
\hline $\begin{array}{c}2 \\
(.7)\end{array}$ & $\begin{array}{c}5 \\
(1.7)\end{array}$ & $\begin{array}{c}20 \\
(6.8)\end{array}$ & $\begin{array}{c}135 \\
(45.8)\end{array}$ & $\begin{array}{c}133 \\
(45.1)\end{array}$ \\
\hline
\end{tabular}

$S D=$ Strongly Disagree; $D=$ Disagree; $U n=$ Undecided; $A=$ Agree; $S A=$ Strongly Agree 
Table 5

Hydration Behaviors of NCAA Track and Field Throwers, No. (\%)

\begin{tabular}{|c|c|c|}
\hline Item & Yes & No \\
\hline $\begin{array}{l}\text { I ingest salt tablets which keeps me from getting dehydrated during training and } \\
\text { competition. }\end{array}$ & $1(0.4)$ & $274(99.6)$ \\
\hline $\begin{array}{l}\text { I drink plenty of fluids so my athletic performance will not decrease due to } \\
\text { dehydration. }\end{array}$ & $246(89.5)$ & $29(8.7)$ \\
\hline I use thirst alone as a way to tell if I am dehydrated. & $50(18.2)$ & $225(81.8)$ \\
\hline I do not drink water or some type of fluid during practice. & $18(6.5)$ & $257(93.5)$ \\
\hline My coach does not allow me to drink fluids during practice. & $3(1.1)$ & $272(98.9)$ \\
\hline My coach does not allow me to drink fluids during competition. & $1(0.4)$ & $274(99.6)$ \\
\hline Fluids are readily available to me during practice. & $215(78.2)$ & $60(21.8)$ \\
\hline Fluids are readily available to me during competition. & $244(88.7)$ & $31(11.3)$ \\
\hline Within 2 hours after exercise, I drink a sports drink. & $99(36.0)$ & $176(64.0)$ \\
\hline I drink sports drinks rather than water to restore glycogen in my muscles. & $54(19.6)$ & $221(80.4)$ \\
\hline I drink $503-591 \mathrm{ml}$ of water or a sports drink a couple of hours before competition. & $216(78.5)$ & $59(21.5)$ \\
\hline I drink $503-591 \mathrm{ml}$ of water or a sports drink 10-20 minutes before competition. & $171(62.2)$ & $104(37.8)$ \\
\hline I drink sports drinks rather than water when exercising for more than an hour. & $75(27.3)$ & $200(72.7)$ \\
\hline I use the color of my urine to determine if I am dehydrated. & $244(88.7)$ & $31(11.3)$ \\
\hline $\begin{array}{l}\text { I weigh myself before and after practice to see how much weight I have lost from } \\
\text { sweating and use this to determine how much water or sports drink to consume. }\end{array}$ & $27(9.8)$ & $248(90.2)$ \\
\hline $\begin{array}{l}\text { I use excessive sweating, thirst, and muscle cramping to warn me if I am becoming } \\
\text { dehydrated. }\end{array}$ & $238(86.5)$ & $37(13.5)$ \\
\hline
\end{tabular}

There were a few behaviors reported by CTFTs that contrasted fluid consumption guidelines. Only $9.8 \%(n=27)$ of CTFTs reported weighing themselves before and after practice to identify sweat loss and volume of fluids needed to restore pre-activity levels. Only $27.3 \%(n=75)$ reported consuming a sports drink over water when exercising for more than one hour, and $19.6 \%(n=54)$ indicated that they drank a sports drink to restore muscle glycogen. Furthermore, only $36 \%(n=99)$ indicated consuming sports drinks within two hours following exercise.

\section{Sources of Nutrition Information}

A total of 269 participants completed all questions related to sources of nutrition information. Formal nutrition education included activities like taking a nutrition class or attending a presentation given by a dietitian or an athletic trainer. The majority $(71.0 \%, \mathrm{n}=233)$ reported having attended a presentation given by an athletic trainer, while others $(37.8 \%, \mathrm{n}=124)$ indicated that they attended a nutrition lecture given by a dietitian. A smaller percentage of participants $(30.8 \%, \mathrm{n}=101)$ took a nutrition course at some point in time.

In addition to formal sources, CTFTs reported numerous other resources that they utilized for "informal" nutrition education. Informal nutrition education denotes a more casual, frequent, and athlete-directed style of obtaining information. Many CTFTs $(87.4 \%, \mathrm{n}=$ 235) indicated that coaches were a source for 
current nutrition information, and 87.4\% ( $\mathrm{n}=231)$ indicated they used the Internet. Closely following, $71.4 \% \quad(\mathrm{n}=192)$ of participants indicated they utilized a physician, and $65.8 \%$ ( $\mathrm{n}=$ $177)$ indicated that they relied upon friends and teammates as a nutrition resource.

\section{Barriers}

A total of 269 participants completed all questions assessing barriers to adequate fluid consumption. While $78.2 \% \quad(\mathrm{n}=215)$ of participants reported that water or other fluids were readily available during practice, additional items revealed that $58.6 \%(n=140)$ of CTFTs cited facility location or practice times influenced the accessibility of water. Furthermore, $90 \%(n=242)$ of CTFTs knew that a healthy diet may help them perform optimally, but only $74.7 \% \quad(\mathrm{n}=201)$ actually intended to eat a diet that would result in optimal performance and $67.7 \% \quad(\mathrm{n}=182)$ indicated that a healthy diet would be enjoyable. However, CTFTs indicated that their classes $(54.6 \%, \mathrm{n}=147)$ and practice schedules $(29.0 \%, \mathrm{n}=$ 78) created barriers to actually consuming such a diet. Also, only 40.5\% $(n=109)$ indicated that their teammates made an effort to eat a proper diet, and only $37.9 \%(\mathrm{n}=102)$ believed that their teammates would want them to eat a proper, performance-enhancing diet.

\section{Discussion}

Research has shown that although athletes understand the importance of rehydration, they may lack the knowledge needed to maintain hydration (Carvalho et al., 2011; Casa et al., 2000; Jonnalagadda et al., 2001). This may impact performance and set the stage for potential adverse medical conditions during vigorous physical activity. Enhanced knowledge can improve attitudes and behaviors, as indicated by the significant and positive correlations identified in this study and previous research (Nichols et al., 2005). The results of the current study indicate that CTFTs are fairly knowledgeable on the topic of hydration, which makes them more likely to consume fluid before dehydration occurs (Table 2). However, some view thirst as the single indicator of hydration status which may not be true in all instances. Previous research has indicated that thirst-guided hydrating leads to dehydration when performing long duration exercise in a hot and humid environment (Wilk and Bar-Or, 1996). While there is some debate about the best manner to acutely determine hydration, it is often recommended that a combination of measures such as body mass and urine osmolality be used (Casa et al., 2000). Since our study did not identify significant correlations between CTFTs who intended to eat a nutritious diet and hydration behaviors, other than consuming $503-591 \mathrm{ml}$ of fluid 2-3 hours prior to activity, there may not be a relationship between those who intended to practice healthy behaviors with their actions.

The appropriate use of sports drinks is not well understood by CTFTs (Nichols et al., 2005; Sawka et al., 2007). The physical demands of CTFTs involve repeated bouts of high-intensity exercise over the course of several hours, suggesting they should be mindful of effective refueling strategies. There is evidence to suggest that the ingestion of a carbohydrate beverage consumed at regular intervals delays fatigue in athletes who participate in intermittent, highintensity exercise (Davis et al., 1997). A recent study also found significantly less weight loss (i.e. water loss) in athletes who consumed a sports drink versus those who consumed water (Carvalho et al., 2011). In addition, only $67.5 \%$ ( $\mathrm{n}=$ 199) of CTFTs in this study reported that a sports drink should be consumed within two hours after exercise. The evidence suggests that rehydrating and refueling post-exercise should occur within two hours and should consist of foods and drinks that contain sodium which will stimulate thirst and assist in the retention of fluids (Casa et al., 2000; Sawka et al., 2007). Sports drinks are readily available and typically contain sodium to meet this need. Since carbohydrate stores are likely low or depleted post-exercise, a sports drink will also serve to provide an adequate supply of carbohydrates and electrolytes that will not hinder rehydration (Casa et al., 2000). One and four tenths of a percent $(1.4 \%, n=122)$ of participants reported that consuming a sports drink would aid in restoring muscle glycogen. During exercise, the goal of consuming a sports drink is to maintain blood glucose levels (Casa et al., 2000). However, post-exercise, the consumption of sports drinks may assist in muscle glycogen restoration. Ultimately, when an athlete needs to quickly rehydrate and/or refuel after exercise, as when preparing for another 
exercise bout, then the use of sports drinks will assist with carbohydrate restoration without compromising gastric emptying (Casa et al., 2000). However, if the exercise session has concluded, rapid fluid replacement may not be as critical, thus ingesting a higher concentration of carbohydrates will be more effective in restoring muscle glycogen (Casa et al., 2000). Our findings indicate that confusion exists regarding the most appropriate use of sports drinks, thus education of athletes in this area is needed.

Fortunately, the CTFTs' attitudes on hydration were positive, as the majority of participants believed that hypohydratoin and dehydration would decrease athletic performance. This is important because hypohydration has been shown to have a negative impact on performance among athletes in certain instances such as in the heat (Casa et al., 2000). However, there were slight contrasts in the CTFTs' attitudes on hydration and their actual behaviors, which is consistent with previous findings in a study conducted on collegiate freshman football players (Jonnalagadda et al., 2001). A high percentage $(81.3 \%)$ of participants believed that consuming 503 - $591 \mathrm{ml}$ of fluid a few hours before competition was important, while $78.5 \%$ reported that they actually consumed that amount. On the other hand, $59.7 \%$ believed that consuming 207 $295 \mathrm{ml}$ of fluid 10-20 min before competition was important, and $62.2 \%$ reported actually consuming that amount. A recent study found a correlation between fluid intake and knowledge scores and fluid intake and behavior scores in high performing adolescent basketball players (Carvalho et al., 2011). The findings in our study indicate that athletes should be more knowledgeable on appropriate ways to practice proper hydration and fueling practices, particularly as it relates to pre-exercise hydration, the indicative value of thirst and the appropriate use of sports drinks. Furthermore, they should be continually encouraged by SCs and athletic trainers to ensure that they consume appropriate amounts of fluids if the exercise type or the environment necessitates more than drinking due to thirst. This is particularly crucial when athletes exercise in the heat, as dehydration will lead to increased core body temperature under this environmental condition making them susceptible to exertional heat illness (Casa et al., 2000).
Knowledge alone is not enough; proper information on application of such knowledge is important as well.

A lack of access to fluids throughout practice or competition can create additional barriers to proper hydration for athletes. The results of the study indicated that facility location or practice times influenced the accessibility of water. These barriers are a result of CTFTs being segregated from the other competitors due to concern that unsuspecting athletes or officials may be struck by flying shots, hammers, discuses and javelins (Judge et al., 2010). This safety-based competitive segregation issue within track and field may be extenuated by the many hours most throwers, who typically possess the largest BMI indexes on track and field teams, spend outdoors during meets. Among runners, this barrier may be most evident when out on a run and away from resources that may provide an opportunity to rehydrate (Judge et al., 2010). Also, water is typically the most widely available option for athletes during competition. Despite the convenience and availability of drinking water, athletes may be less likely to consume water unless it is flavored and has greater taste appeal (Bar-Or and Wilk, 1996). However, in the present study, the majority of athletes disagreed with the statement that sports drinks were better than water. All of these factors can present challenges for rehydrating and refueling during training or competition.

The majority of CTFTs indicated that their sources of nutrition information were their coaches and the Internet. Thus, a team approach should be implemented between coaches and strength and conditioning professionals to educate and encourage proper hydration practices. Both field event coaches and SCs can implement ways for their athletes to practice proper hydration behaviors, including the use of a urine color chart, which is one of the easiest ways for athletes to self-assess their hydration status (Volpe et al., 2009).

Results of this study indicate that CTFTs are generally knowledgeable about proper refueling and hydration, but do not always put that knowledge into practice. Confusion exists on the proper utilization of carbohydrate-electrolyte beverages (i.e. sports drinks) for rehydrating and refueling, thus education in this area is warranted. 
Education on the behalf of SCs could clear the confusion with regard to the optimal beverage for rehydrating based on the needs of the athlete. Close monitoring by SCs, such as weigh-ins before and after practices and competitions, could also enhance hydration practices so that athletes can see how much fluid was lost through sweat during activity. Since coaches are a primary source for nutritional information, it is critical that coaches convey the most accurate and up-to-date information, and encourage athletes to practice appropriate hydration strategies. Therefore, SCs should work closely with the field event coaches to provide evidence-based resources in the area of hydration that would be of value to CTFTs. Since CTFTs may, at times, be segregated from the rest of the competitors at meets, which could lead to a lack of resources for them to stay hydrated, it is important for SCs to ensure that all participants, regardless of where they compete, have access to fluids in order to prevent dehydration.

It is important to acknowledge the limitations of the current study. There are some factors to consider that may have affected the results of the present study. On the perception scale, participants may have attempted to present themselves and their perceptions in a more positive light, and participants potentially may have worried about the perceived repercussions caused from their answers. While the current sample is adequate to present the findings of the study, a larger sample may have revealed additional findings of importance. This descriptive study did not include important qualitative aspects like dialogue with ATs about the hydration status of CRFTs, nor with CTFTs about their attitudes toward use of an isolated facility with limited access to hydration. Giving voice to the viewpoints expressed in the survey data could have added depth to the results. The discussion of the study, therefore, was limited to issues potentially surrounding the quantitative descriptive data collected. Future studies related to this research should extend to other populations of athletes in order to gather results more generalizable to all sports.

\section{References}

Azoulay A, Garzon P, Eisenberg MJ. Comparison of the mineral content of tap water and bottled waters. J Gen Intern Med, 2001; 16(3): 168-175.

Baker LB, Barnes KA, Anderson ML, Passe DH, Stofan JR. Normative data for regional sweat sodium concentration and whole-body sweating rate in athletes. J Sports Sci, 2016; 34: 358-363

Bar-Or O, Wilk B. Water and electrolyte replenishment in the exercising child. Int J Sport Nutr, 1996; 6: 93-99

Berning J, Steen SN. Sports Nutrition for the Nineties: The Health Professional's Handbook. Gaithersburg, MD: Aspen Publishers Inc., 153 - 174; 1991

Carvalho P, Oliveira B, Barros R, Padrão P, Moreira P, Teixeira VH. Impact of fluid restriction and ad libitum water intake or an $8 \%$ carbohydrate-electrolyte beverage on skill performance of elite adolescent basketball players. Int J Sport Nutr Exerc Metab, 2011; 21: 214-221

Casa DJ, Armstrong LE, Hillman SK, Montain SJ, Reiff RV, Rich BS, Roberts WO, Stone JA. National Athletic Trainers' Association position statement: Fluid replacement for athletes. J Athl Train, 2000; 35: 212-224

Casa DJ, Cheuvront SN, Galloway SD, Shirreffs SM. Fluid needs for training, competition, and recovery in track-and-field athletes. Int Journal Sport Nutr Exerc Meta, 2019; 29: 175-180

Cheuvront S, Kenefick R. Dehydration: Physiology, assessment, and performance effects. Compr Physiol, 2014; 4: 257-285

Chycki J, Zajac T, Maszczyk A, Kurylas A. The effect of mineral-based alkaline water on hydration status and metabolic response to short-term anaerobic exercise. Bio Sport, 2017; 34(3): 255-261

Davis JM, Jackson DA, Broadwell MS, Queary JL, Lambert CL. Carbohydrate drinks delay fatigue during intermittent, high-intensity cycling in active men and women. Int J Sport Nutr, 1997; 7: 261-273

Jones LC, Cleary MA, Lopez RM, Zuri RE, Lopez R. Active dehydration impairs upper and lower body anaerobic muscular power. J Strength Cond Res, 2008; 22: 455 
Jonnalagadda SS, Rosenbloom CA, Skinner R. Dietary practices, attitudes, and physiological status of collegiate freshman football players. J Strength Cond Res, 2001; 15: 507-513

Judelson DA, Maresh CM, Anderson JM, Armstrong LE, Casa DJ, Kraemer WJ, Volek JS. Hydration and muscular performance: Does fluid balance affect strength, power and high-intensity endurance? Sports Med, 2007; 37: 907-921

Judge LW, Bellar DM, Gilreath EL, Petersen JC, Craig BW, Popp JK, Hindawi OS, Simon LS. An examination of preactivity and postactivity stretching practices of NCAA Division I, NCAA Division II, and NCAA Division III track and field throws programs. J Strength Cond Res, 2013; 27: 2691-2699

Judge LW, Kumley RF, Bellar DM, Pike KL, Pierson EE, Weidner T, Pearson D, Friesen CA. Hydration and fluid replacement knowledge, attitudes, barriers, and behaviors of NCAA Division 1 American football players. J Strength Cond Res, 2016; 30: 2972-2978

Judge LW, Petersen JC, Bellar DM, Gilreath E, Yurko R. NCAA division I, II, and II collegiate track and field hammer throw facilities: Compliant with international safety standards? J Venue Event Manag, 2010; 2: $15-28$

Maughan R, Shirreffs S. Development of hydration strategies to optimize performance for athletes in highintensity sports and in sports with repeated intense efforts. Scand J Med Sci Sports, 2010; 20: 59-69

Nichols PE, Jonnalagadda SS, Rosenbloom CA, Trinkaus M. Knowledge, attitudes, and behaviors regarding hydration and fluid replacement of collegiate athletes. Int J Sport Nutr Exerc Metab, 2005; 15: 515-527

O'Neal EK, Wingo JE, Richardson MT, Leeper JD, Neggers YH, Bishop PA. Half-marathon and fullmarathon runners' hydration practices and perceptions. J Athl Train, 2011; 46: 581-591

Savoie FA, Kenefick RW, Ely BR, Cheuvront SN, Goulet ED. Effect of hypohydration on muscle endurance, strength, anaerobic power and capacity and vertical jumping ability: A meta-analysis. Sports Med, 2015; 45: 1207-1227

Sawka MN, Burke LM, Eichner ER, Maughan RJ, Montain SJ, Stachenfeld NS. American College of Sports Medicine position stand. Exercise and fluid replacement. Med Sci Sports Exerc, 2007; 39: 377-390

Volpe SL, Poule KA, Bland EG. Estimation of prepractice hydration status of National Collegiate Athletic Association Division I athletes. J Athl Train, 2009; 44: 624-629

Wilk B, Bar-Or O. Effect of drink flavor and $\mathrm{NaCL}$ on voluntary drinking and hydration in boys exercising in the heat. J Appl Physiol, 1996; 80: 1112-1117

Yeargin SW, Casa DJ, Judelson DA, McDermott BP, Ganio MS, Lee EC, Lopez RM, Stearns RL, Anderson JM, Armstrong LE, Kraemer WJ, Maresh CM. Thermoregulatory responses and hydration practices in heat-acclimatized adolescents during preseason high school football. J Athl Train, 2010; 45: 136-146

\section{Corresponding author:}

\section{Lawrence W. Judge}

Ball State University, 2000 W University Ave Muncie, IN 47306

Phone Number: (765) 285-4211

Fax Number: (765) 285-8254

Email: lwjudge@bsu.edu 